\title{
Poly(acrylonitrile-co-butadiene-co-styrene) Reinforced with Hollow Glass Microspheres: Evaluation of Extrusion Parameters and Their Effects on the Composite Properties
}

\author{
Marina Panozzo Cunha, ${ }^{1}$ Laura Berasain Gonella, ${ }^{2}$ Matheus Poletto, ${ }^{1}$ \\ Ana Maria Colon Grisa, ${ }^{1}$ and Rosmary Nichele Brandalise ${ }^{1}$ \\ ${ }^{1}$ Center for Exact Sciences and Technology, University of Caxias do Sul, Rua Francisco Getúlio Vargas 1130, \\ 95070-560 Caxias do Sul, RS, Brazil \\ ${ }^{2}$ Rio Grande do Sul Federal Institute of Education, Science and Technology, Rua Avelino Antonio de Souza 1730, \\ 95043-700 Caxias do Sul, RS, Brazil
}

Correspondence should be addressed to Rosmary Nichele Brandalise; rnbranda@ucs.br

Received 13 March 2016; Revised 30 May 2016; Accepted 8 June 2016

Academic Editor: Pasquale Longo

Copyright (c) 2016 Marina Panozzo Cunha et al. This is an open access article distributed under the Creative Commons Attribution License, which permits unrestricted use, distribution, and reproduction in any medium, provided the original work is properly cited.

Hollow glass microspheres (HGMs) filled poly(acrylonitrile-co-butadiene-co-styrene) (ABS) composites were prepared by means of a twin-screw extruder. S038 HGMs were incorporated at different percentages of 2.5, 5.0, and 7.5 wt $\%$. The HGMs were added into the twin-screw extruder at two different feeding zones, and the effect of HGMs loading and specific feeding zone addition on the composites produced was evaluated with regard to morphological, thermal, rheological, physical, and mechanical properties. As a result, the composite density was reduced while the thermal stability, storage modulus, complex viscosity, and tensile and flexural modulus were improved when compared with the ABS matrix. The results also indicate that the addition of $5.0 \mathrm{wt} \%$ of $\mathrm{HGMs}$ at the feeding zone closer to the die maintains the integrity of the HGMs and promotes composites with higher mechanical properties and lower density when compared with the composites obtained with the addition of HGMs closer to the hopper.

\section{Introduction}

Marine, aerospace, and automotive structural applications strive for low density materials having high strength, modulus, and damage tolerance [1-3]. In addition, the regulatory requirements on low $\mathrm{CO}_{2}$ emission and environmental concerns [2] are a challenge for automotive industries to promote vehicle weight reduction without compromise of its performance. Polymer composite materials reinforced with hollow glass microspheres are generally designed to comprise low density materials with higher mechanical performance [2-6].

Poly(acrylonitrile-co-butadiene-co-styrene) (ABS) is employed in the automotive industry, normally in the interior of vehicles as a function of its impact strength and outstanding balance between strain, modulus of elasticity, and tensile and flexural strength, combined to its low cost $[4,7]$. Specific properties designed for different applications result from changes in proportions and monomers applied in its polymerization [8-11]. Acrylonitrile monomer contributes to the property of thermal and chemical resistance, while butadiene monomer provides impact resistance and flexibility and styrene monomer adds to processability and stiffness [9].

Hollow glass microspheres (HGMs) are used to reduce weight and to impart specific properties to polymer materials for various applications [2]. HGMs are characterized by being hollow glass spheres having average diameter of 15 to $65 \mathrm{~mm}$ with very thin walls of 0.5 to $1.5 \mathrm{~mm}$ and mainly of density from 0.12 to $0.60 \mathrm{~g} \cdot \mathrm{cm}^{-3}$, the addition of these spheres causing in general nearly no effect when processing the composite in view of the low amounts incorporated [10].

Several thermoplastic composites reinforced with HGMs were prepared in a conventional screw extruder, batch mixer, 
or injection molding. Liang [4] studied the mechanical properties of three types of ABS composites filled with hollow glass beads with different sizes and size distributions using a twin-screw extruder. The author observed that the mechanical properties increase at filler volume fraction of $5 \%$, and the effects of filler size and its distribution on the mechanical properties evaluated are not significant. In a more recent study, Liang and coworkers [12] evaluated the correlation between impact strength and surface fracture dimension for ABS filled with hollow glass beads. The authors verified that the IZOD impact strength of the composite decreases quickly with increasing volume fraction of the filler for the volume fraction from 0 to $5 \%$. In addition, the surface fractal dimension was an exponential function of the impact strength of the ABS/hollow glass bead composites. However, the effect of different extruder feeding zones on the properties of ABS reinforced by HGMs processed at a twinscrew extruder has not been fully explored. The twin-screw extruder can promote a more disperse and distributed mixing of the HGMs into the polymer matrix which may promote lighter composites with higher mechanical properties.

So the present work aims at developing ABS composites with different HGM loading in a twin-screw extruder, evaluating the effect of the addition of HGM at two different extruder feeding zones on the morphological, thermal, rheological, physical, and mechanical properties of the composites. The developed composite has potential application in the automobile industry, based on the reduction of composite density and improvement in the mechanical properties evaluated.

\section{Experimental}

2.1. Materials. ABS SV-0165 is supplied by Samsung Starex, China, with impact strength (ASTM D256-10) of $245 \mathrm{~J} \cdot \mathrm{m}^{-1}$. Hollow glass microsphere (HGM), type S038HS, without surface treatment is supplied by $3 \mathrm{M}^{\mathrm{TM}}$ of Brazil (Glass Bubbles $^{\circledast}$ ). HGM density is $0.98 \mathrm{~g} \cdot \mathrm{cm}^{-3}$ and compression strength is $34.5 \mathrm{MPa}$. For measurement the composite density used ethanol PA supplied by Merck with purity equal to $99.9 \%$.

\subsection{Procedure for the Preparation of Composites. ABS SV-165} was dried in a Marconi (Brazil) oven, with air circulation for 24 hours at $60^{\circ} \mathrm{C}$ [13]. Composites were processed in $\mathrm{MH}$ Equipamentos (Brazil) and corotating and interpenetrating twin-screw extruder with length/diameter (L/D) ratio of $32 \mathrm{~mm}$ and $20 \mathrm{~mm}$ screw with rotating speed $100 \mathrm{rpm}$ and temperature profile $200-200-230-240^{\circ} \mathrm{C}$ [13]. HGM incorporation into the composites during extrusion at the percentages of $2.5,5.0$, and $7.5 \mathrm{wt} \%$ was performed at two distinct feeding zones:

(i) Z1 feeding point: incorporation of ABS SV-0165 and HGM at the extruder feeding point, dosage performed with volumetric feeder.

(ii) Z2 feeding point: HGM incorporation at the central extruder zone, the incorporation being performed

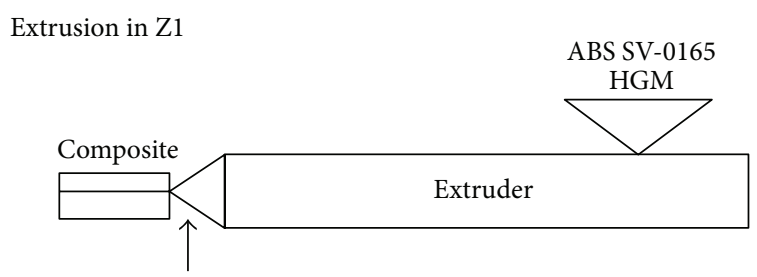

(a)

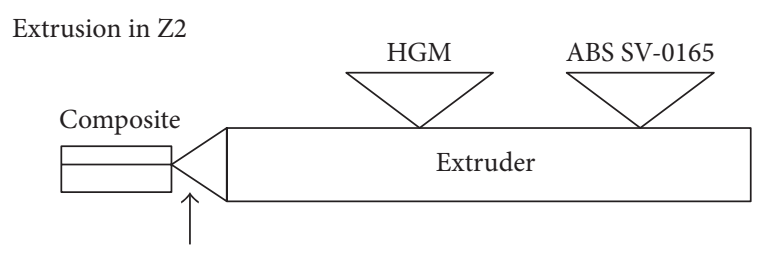

(b)

FIGURE 1: (a) HGM incorporation at the feeding zone with 2.5, 5.0, and 7.5 wt.\% HGM + ABS incorporated at Z1; (b) incorporation of HGM at the central extruder zone (Z2) with 2.5, 5.0, and $7.5 \mathrm{wt} . \%$ HGM and ABS incorporated at Z1.

TABLE 1: Codification and composition of the ABS composites with hollow glass spheres and double screw extruder feeding zones.

\begin{tabular}{lcc}
\hline Samples & HGM (wt.\%) & Incorporation zone HGM \\
\hline ABS2.5-Z1-S038 & 2.5 & $\mathrm{Z} 1$ \\
ABS5.0-Z1-S038 & 5.0 & $\mathrm{Z} 1$ \\
ABS7.5-Z1-S038 & 7.5 & $\mathrm{Z1}$ \\
ABS2.5-Z2-S038 & 2.5 & $\mathrm{Z} 2$ \\
ABS5.0-Z2-S038 & 5.0 & $\mathrm{Z} 2$ \\
ABS7.5-Z2-S038 & 7.5 & $\mathrm{Z} 2$ \\
\hline
\end{tabular}

with MH Equipamentos (Brazil) side feeder. ABS SV0165 was incorporated at the (Z1) extruder feeding zone (Figure 1).

Compositions used in this study are listed in Table 1.

2.3. Characterization of Materials and Composites. Plates were produced by compression molding at the dimensions of $165 \times 95 \times 3 \mathrm{~mm}$ in a model 30010-4-1 (Brazil) press, at a pressure of 60 bar for 12 minutes, and at $170^{\circ} \mathrm{C}$ and cooled to $60^{\circ} \mathrm{C}[11]$. Specimens for mechanical tests were obtained from plates cut using a band saw.

Morphological characterization was performed in a Shimadzu (Japan) scanning electron microscope (SEM) at an accelerating voltage of $15 \mathrm{kV}$, fractured by liquid nitrogen, the surface to be tested being coated with gold.

Density was evaluated in accordance with the ASTM D4052-95 Method by the pycnometer method. HDT analysis made use of a Ceast instrument of the Polimate brand (Brazil), in accordance with the ASTM D648-07 Method.

Rheological properties were analyzed in Anton Paar Physica MCR 101 (USA) parallel plate oscillating rheometer in accordance with the ASTM D7395-07 Method, with frequency variation of 0.01 and $100 \mathrm{rad} \cdot \mathrm{s}^{-1}$ and temperature from 180 to $200^{\circ} \mathrm{C}$ under a nitrogen atmosphere, at a rate of 


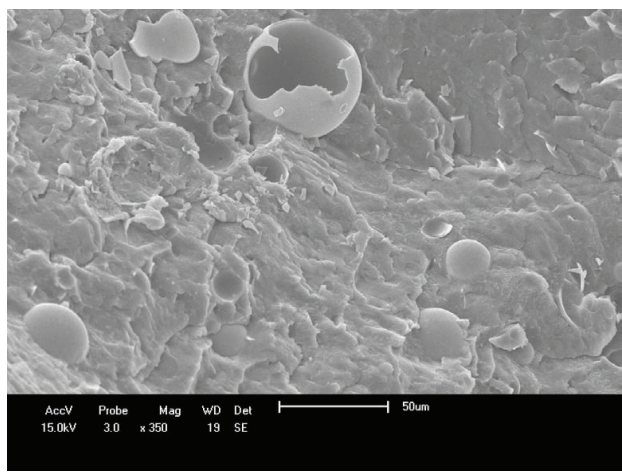

(a)

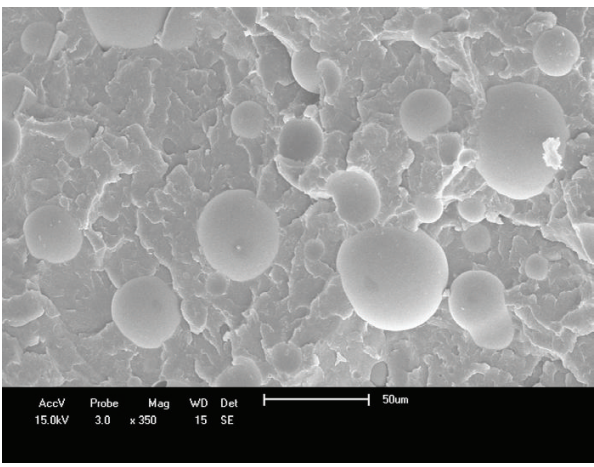

(c)

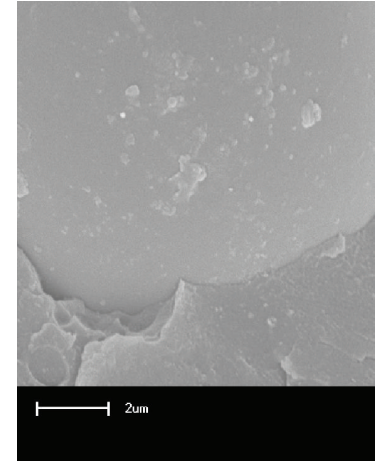

(b)

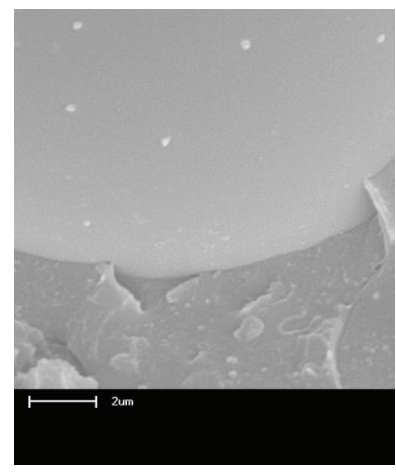

(d)

FIGURE 2: SEM micrographs of the 7.5\% mass HGM composites fractured section (a) with reinforcement incorporation at the extruder feeding zone (Z1) of ABS7.5/Z1/S038 composite and (b) insert expanding the region of interaction between HGM and ABS of the ABS7.5/Z1/S038 composite (c) with reinforcement incorporation at the extruder central zone (Z2) of the ABS7.5/Z2/S038 composite and (d) insert expanding the region of interaction between HGM and ABS of the ABS7.5/Z2/S038 composite.

$10^{\circ} \mathrm{C} \cdot \mathrm{min}^{-1}$, the test specimens having $20 \mathrm{~mm}$ diameter and $3 \mathrm{~mm}$ height [14].

Tensile strength was measured in accordance with the ASTM D638-10 Method in EMIC (Brazil) instrument model DL 2000, at a speed of $50 \mathrm{~mm} \cdot \mathrm{min}^{-1}$ with test specimens of $165 \times 13.3 \times 3 \mathrm{~mm}$ dimensions. Flexural strength was determined in accordance with the ASTM D790-A0 Method in the same equipment cited above, at a speed of $0.9 \mathrm{~mm} \cdot \mathrm{min}^{-1}$ and test specimens of $127 \times 12.7 \times 3 \mathrm{~mm}$. IZOD impact strength was measured in accordance with ASTM D256-10 Method in a Polimate model Ceast Resil equipment (Brazil) with a $4 \mathrm{~J}$ pendulum and $63 \times 12.7 \times 3 \mathrm{~mm}$ notch. All test specimens sides were filed with 80 grain sandpaper supplied by $3 \mathrm{M}$ of Brazil. The values for all mechanical properties correspond to the median of 7 test specimens.

Statistical analysis (ANOVA) was performed using Excel 2010 software.

\section{Results and Discussion}

3.1. Morphological Properties. SEM micrographs of the $7.5 \mathrm{wt} \%$ HGM composites are shown in Figure 2 with incorporation at the feeding zone (Z1) and at the central feeding zone (Z2).

In Figure 2(a) it is possible to observe that some HGMs were removed from the matrix at the time of the fracture caused by reduced chemical affinity between reinforcement and matrix. Also a homogenous distribution of HGM in ABS was observed as a result of the reinforcement incorporation at Z1.

It could be seen that the HGM kept their integrity after extrusion at Z2, but considering the magnitude of Figure 2(c) micrographs (350x), higher number of HGMs is noticed in the observed region, with reinforcement agglomeration, as compared with the morphology of Figure 2(a) (350x).

Enlargement of the reinforcement-matrix interface is presented in Figures 2(b) and 2(d), where it is possible to determine the presence of voids among the ABS matrix and the HGM, which configures a weak interaction which supports microspheres removal at the moment of fracture.

Jo et al. [7] evaluated the mechanical properties of polyurethane (PU) reinforced by HGMs. The authors observed that an interaction between reinforcement and matrix was promoted by hydroxyl groups $-\mathrm{OH}$ of the microsphere surface with carbonyl groups $(\mathrm{C}=\mathrm{O})$ and $\mathrm{PU}$ methylene groups $\left(-\mathrm{CH}_{3}\right)$. ABS polarity is restricted to the acrylonitrile monomer, the remaining of its structure being of a nonpolar character. In this study the interaction between matrix and reinforcement, if any, would be due to intermolecular attraction forces among these microsphere surface $-\mathrm{OH}$ chemical groups and acrylonitrile. 
TABLE 2: Density and HDT of the composites as a function of the hollow glass microspheres percentage with ANOVA statistical analysis for the variations encountered in the study.

\begin{tabular}{ccc}
\hline Samples & Density $\left(\mathrm{g} \cdot \mathrm{cm}^{-3}\right)$ & HDT $\left({ }^{\circ} \mathrm{C}\right)$ \\
\hline ABS/B (control) & $1.04 \pm 0.001$ & $83.3 \pm 0.4$ \\
ABS2.5/Z1/SO38 & $1.04 \pm 0.001$ & $86.0 \pm 0.7$ \\
ABS5.0/Z1/SO38 & $1.02 \pm 0.006$ & $82.9 \pm 1.2$ \\
ABS7.5/Z1/SO38 & $1.06 \pm 0.002$ & $85.7 \pm 1.1$ \\
ABS2.5/Z2/SO38 & $0.97 \pm 0.004$ & $83.5 \pm 0.9$ \\
ABS5.0/Z2/SO38 & $0.98 \pm 0.001$ & $84.6 \pm 0.9$ \\
ABS7.5/Z2/SO38 & $0.96 \pm 0.004$ & $83.0 \pm 0.9$ \\
\hline
\end{tabular}

\begin{tabular}{|c|c|c|c|c|c|c|c|}
\hline \multicolumn{8}{|c|}{ ANOVA-density } \\
\hline Source of variation & SQ & $\mathrm{gl}$ & MQ & $F$ & Value $P$ & $F$ critical & Significant \\
\hline $\mathrm{Z} 1$ and $\mathrm{Z} 2$ & 0.009 & 11 & 0.01 & 17.78 & 0.002 & 4.965 & Yes \\
\hline $\begin{array}{l}\text { HGM wt.\% } \\
2.5 / 5.0 / 7.5\end{array}$ & 0.009 & 11 & 0 & 0.008 & 0.992 & 4.256 & No \\
\hline \multicolumn{8}{|c|}{ ANOVA-HDT } \\
\hline Source of variation & SQ & $\mathrm{gl}$ & MQ & $F$ & Value $P$ & $F$ critical & Significant \\
\hline $\mathrm{Z} 1$ and $\mathrm{Z} 2$ & 15.24 & 11 & 2.9 & 2.35 & 0.156 & 4.965 & No \\
\hline $\begin{array}{l}\text { HGM wt.\% } \\
2.5 / 5.0 / 7.5\end{array}$ & 15.24 & 11 & 4.41 & 6.18 & 0.02 & 4.256 & Yes \\
\hline
\end{tabular}

3.2. Density and Thermal Properties of Composites. Density and HDT values of the composites studied are presented in Table 2.

Density values of samples fed at $\mathrm{Z} 1$ were between 1.01 and $1.06 \mathrm{~g} \cdot \mathrm{cm}^{-3}$. Samples fed at $\mathrm{Z} 2$ had density values between 0.96 and $1.01 \mathrm{~g} \cdot \mathrm{cm}^{-3}$, which confirm the results obtained in SEM micrographs. When the microspheres were added at Z2 their integrity was preserved, probably because the HGMs are submitted to lower shear forces when fed at this zone, as compared with those fed at Z1. As a consequence, less HGMs are broken during the extrusion process and the composite density values are lower than those observed for samples obtained from HGMs fed at Z1.

The composite of lowest density among the extrudates was the ABS7.5/Z2/S038 sample with $7.5 \mathrm{wt} \% \mathrm{HGM}$, resulting in a density of $0.96 \mathrm{~g} \cdot \mathrm{cm}^{-3}$, which is $8 \%$ lower than that of $\mathrm{ABS} / \mathrm{B}$. For this property, the microspheres insertion location at $\mathrm{Z} 2$ was significant according to the statistical analysis listed in Table 2, indicating that the reinforcement integrity could have been higher at this feeding zone.

HDT results at $\mathrm{Z} 1$ varied between 82.9 and $85.7^{\circ} \mathrm{C}$ and at Z2 between 81.7 and $84.6^{\circ} \mathrm{C}$. HDT values obtained for $\mathrm{HMG}$ composites at $\mathrm{Z1}$ were $2 \%$ higher than the values obtained for $\mathrm{ABS} / \mathrm{B}$, which was extruded in the absence of HGM. For composites obtained by incorporation at $\mathrm{Z} 2$, values were equivalent to those of ABS/B. In accordance with statistical analysis (Table 2), the wt\% of incorporated HGM variable was significant with regard to HDT. The change in thermal behavior by HDT, according to Scaffaro et al. [15], was attributed to the composite increased stiffness imparted by microspheres which as a consequence requires more energy for molecular mobility.

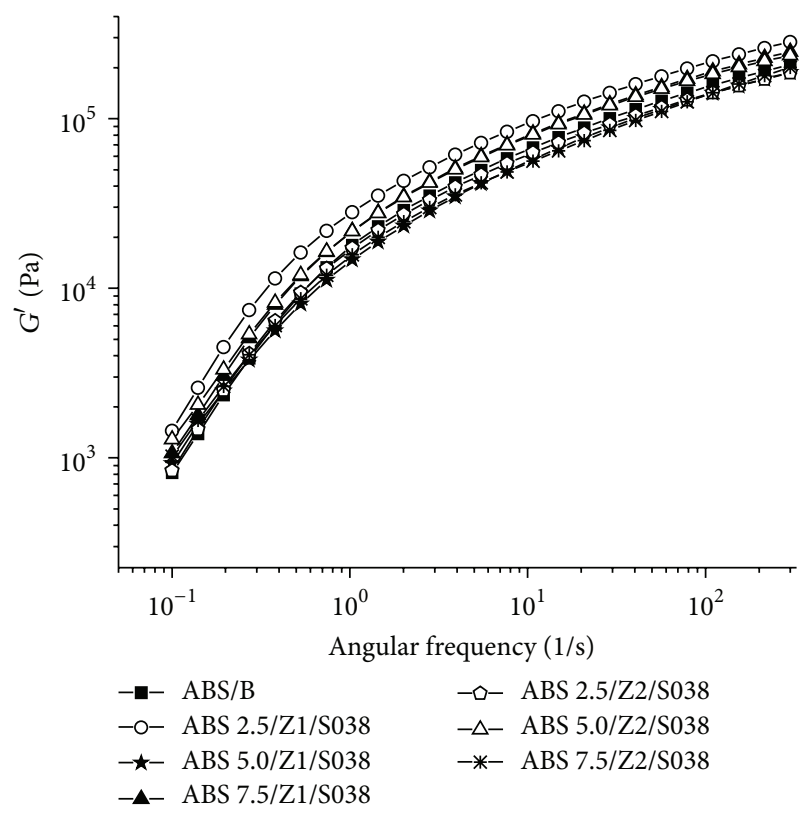

FIGURE 3: Storage modulus $\left(G^{\prime}\right)$ versus angular frequency for ABS/B and for ABS with 2.5, 5.0, and $7.5 \mathrm{wt} \%$ HGM, the reinforcement being incorporated at feeding zone $(\mathrm{Zl})$ and at the extruder center (Z2).

3.3. Rheological Properties. Rheological results are shown in Figure 3.

Composites obtained at Z1 (ABS2.5/Z1/S038, ABS5.0/Z1/ S038, and ABS7.5/Z1/S038) and Z2 (ABS5.0/Z2/S038 and ABS7.5/Z2/S038) had superior storage modulus $\left(G^{\prime}\right)$ values when compared with ABS/B. Storage modulus represents the amount of energy stored by a material during strain 


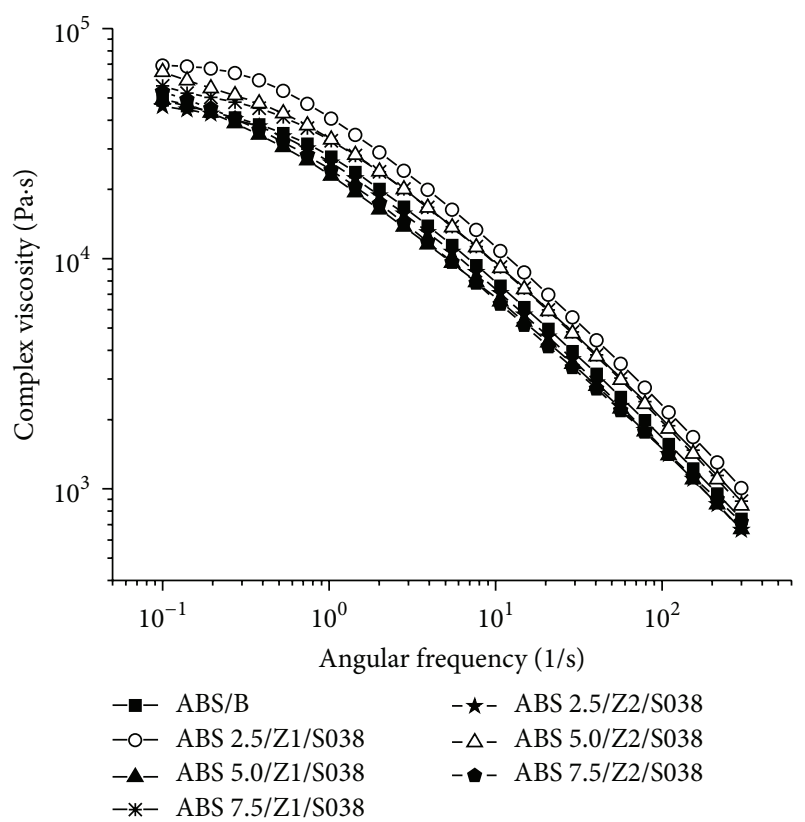

Figure 4: Complex viscosity $\left(\eta^{*}\right)$ versus angular frequency for $\mathrm{ABS} / \mathrm{B}$ and for ABS with 2.5, 5.0, and $7.5 \mathrm{wt} \%$ HGM with the reinforcement incorporated at feeding zone (Z1) and at extrusion center (Z2).

imposed by frequency at a certain temperature, indicating that the polymer relaxations can be hindered by the applied reinforcement and by the homogeneous distribution thereof in the matrix with consequent stiffness increase, while the $\mathrm{ABS} / \mathrm{B}$ composite has no restrictions to molecular mobility, since it does not bear any kind of reinforcement.

A further aspect to be considered for the increased $G^{\prime}$ values was reported by $\mathrm{Li}$ et al. [16] on poly(butylene succinate) (PBS) and HGM, the homogeneous distribution of the reinforcement throughout the PBS matrix and the formation of a kind of network, the two factors being responsible for the augmented $G^{\prime}$ value.

In Figure 3 it is possible to observe that the slope of the $G^{\prime}$ curves for ABS/B and for the HGM composites did not alter with frequency increase at a certain temperature, this behavior having also been observed in a study by Jiang et al. [17], with ABS reinforced with calcium carbonate nanoparticles, indicating that the addition of filler did not alter neither the microstructures nor the rheological nature of ABS.

Complex viscosity for $\mathrm{ABS} / \mathrm{B}$ and the composites is seen in Figure 4.

Complex viscosity values for $\mathrm{Z} 1$ composites (ABS2.5/Z1/ S038 and ABS7.5/Z1/S038) were higher than those for ABS/B. At $\mathrm{Z} 2$, the value for the ABS5.0/Z2/S038 composite was higher than that for ABS/B. Values for the other composites were similar to those of $\mathrm{ABS} / \mathrm{B}$. According to studies by Santos et al. [8] with polyamide (PA) and organophilic montmorillonite clay, the rise in complex viscosity was attributed to flow and movement restriction of polymer chains caused by reinforcement. Complex viscosity results corroborate $G^{\prime}$ results, since $\mathrm{Zl}$ provided higher viscosity

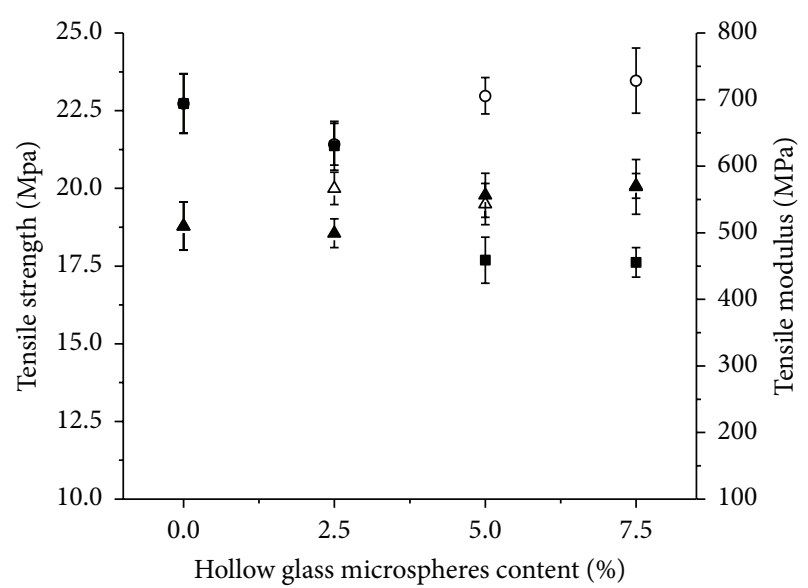

- Tensile ABS Z1 $\quad \Delta$ Tensile modulus ABS Z1

- Tensile ABS Z2 $\quad \Delta$ Tensile modulus ABS Z2

\begin{tabular}{lccccccc}
\hline \multicolumn{7}{c}{ ANOVA-tensile strength } \\
Source of variation & SQ & gl & MQ & $F$ & Value $P$ & $F$ critical & Significant \\
\hline Z1 and Z2 & 35.61 & 11 & 12.7 & 5.565 & 0.04 & 4.965 & Yes \\
HGM wt.\% & 35.61 & 11 & 1.3 & 0.356 & 0.71 & 4.256 & No \\
\hline $2.5 / 5.0 / 7.5$ & & & & &
\end{tabular}

FIgURE 5: Tensile strength and tensile modulus of elasticity for $\mathrm{ABS} / \mathrm{B}$ and for ABS with 2.5, 5.0, and $7.5 \mathrm{wt} \% \mathrm{HGM}$, the reinforcement being incorporated at the ( $\mathrm{Z1})$ feeding zone and at the ( $\mathrm{Z} 2)$ extruder center with statistical analysis.

values when compared with $\mathrm{Z} 2$. This results from the fact that homogenous HGM distribution in the polymer matrix is more accentuated at this feeding zone.

3.4. Mechanical Properties. Tensile strength and tensile modulus according to HGM loading into the composite formulations are shown in Figure 5.

Reduced values for tensile strength by HGM incorporation were observed, with consequent increase in modulus of elasticity. Higher tensile strength values were observed for the composites processed at Z1 relative to Z2, which has been confirmed by statistical analysis (Figure 5 ), in which the HGM incorporation zone significantly influenced the results obtained.

Lower tensile strength values at $\mathrm{Z} 2$ were attributed to nonhomogeneous reinforcement distribution in the matrix, with formation of HGM agglomerates. Li et al. [16], in their studies of PBS with HGM, also attributed the diminished tensile strength to formation of reinforcement agglomeration regions.

Results for composite tensile modulus (Figure 5) were higher; when compared to the ABS/B control sample the best results are obtained for the ABS7.5/Z1/S038 and ABS7.5/Z2/S038 composites. The Z1 feeding zone provided the best modulus values as a function of better reinforcement distribution in the matrix, which cooperates for increased composite stiffness, as already observed by SEM micrographs and storage modulus $\left(G^{\prime}\right)$; however this feeding zone contributes to fracturing HGMs which results in increased composite density. 


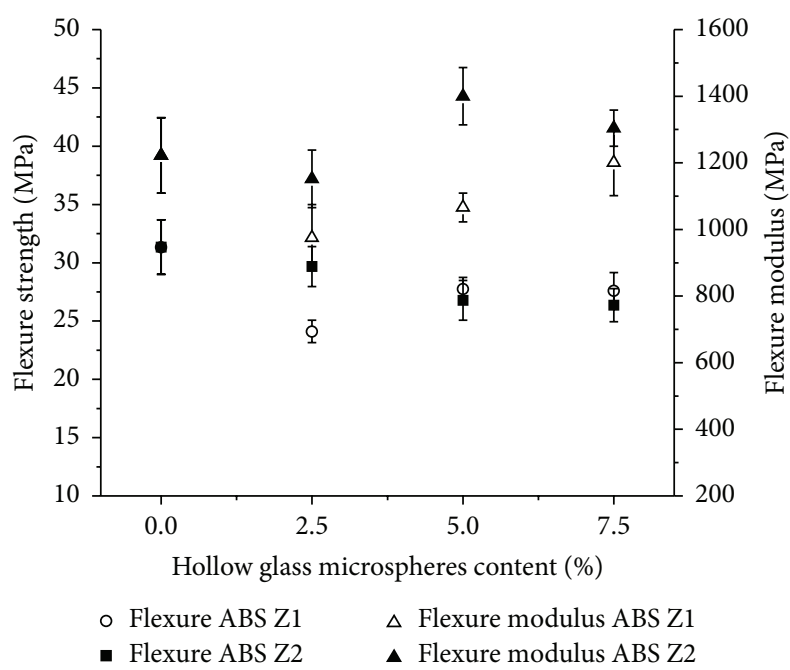

\begin{tabular}{lccccccc}
\hline & \multicolumn{7}{c}{ ANOVA-flexure strength } \\
Source of variation & SQ & gl & MQ & $F$ & Value $P$ & $F$ critical & Significant \\
\hline Z1 and Z2 & 35.61 & 11 & 1.35 & 0.395 & 0.544 & 4.965 & No \\
HGM wt.\% & 35.61 & 11 & 4.15 & 1.365 & 0.303 & 4.965 & Yes \\
\hline
\end{tabular}

FIgURE 6: Flexural strength and flexural modulus of elasticity for $\mathrm{ABS} / \mathrm{B}$ and for $\mathrm{ABS}$ with 2.5, 5.0, and $7.5 \mathrm{wt} \% \mathrm{HGM}$, the reinforcement being incorporated at the $(\mathrm{Z1})$ feeding zone and at the extruder center (Z2), with statistical analysis.

Figure 6 shows the results obtained for flexural strength and flexural modulus.

The flexural strength is associated with the action imparted by reinforcement to the polymer matrix, and microsphere agglomerates can provide different information on flexural strength, as well as the absence of these agglomerates at certain locations of the matrix. Yalcin et al. [9] by adding $18.5 \%$ of hollow glass microspheres and wood flour to a HDPE composite observed a $21 \%$ reduction in flexural strength; this results from the fact that reinforcement reduces the flexibility of the polymer matrix and that wood flour is a filling filler.

Flexural strength results did not show any relevant differences relative to the different zones of HGM incorporation, since at both zones the value for this property was reduced. The flexural modulus increased with HGM incorporation; this increase may be attributed to stiffness imparted by the reinforcement to the matrix $[18,19]$ as can also be seen for tensile modulus. With the increasing of HGM loading the flexural strength decreases, and this difference is significant, as can be seen from the statistical analysis presented in Figure 6.

Figure 7 shows impact resistance versus the HGM percentage incorporated into the composites.

As related to the different HGM feeding zones, reduced values were observed for the impact strength at $\mathrm{Zl}$, with $37 \%$ reduction for $\mathrm{Z} 1$, while at $\mathrm{Z} 2$ the reduction was $30 \%$, both being relative to results for $\mathrm{ABS} / \mathrm{B}$. This behavior was also evidenced for results observed for $G^{\prime}$, in which $\mathrm{Z1}$ had superior stiffness values. According to statistical analysis (Figure 7) the HGM incorporation zone was the critical

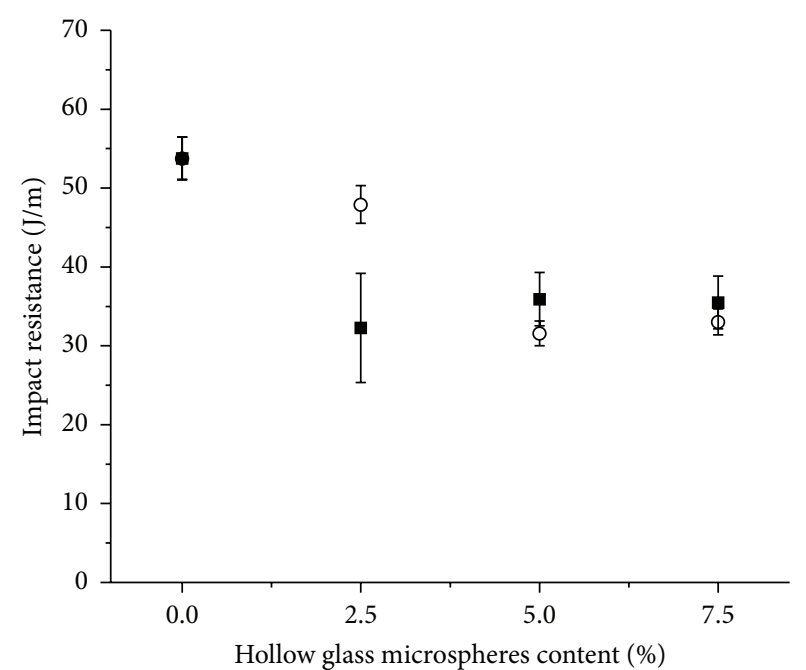

- Impact ABS Z1

- Impact ABS Z2

\begin{tabular}{lccccccc}
\hline & \multicolumn{8}{c}{ ANOVA-impact resistance } & \\
Source of variation & SQ & gl & MQ & $F$ & Value $P$ & $F$ critical & Significant \\
\hline Z1 and Z2 & 399 & 11 & 107 & 3.663 & 0.085 & 3.663 & Yes \\
HGM wt.\% & 399 & 11 & 3.14 & 0.072 & 0.931 & 4.256 & No \\
$2.5 / 5.0 / 7.5$ & & & & & & & \\
\hline
\end{tabular}

FIGURE 7: Impact resistance for ABS/B and for ABS with 2.5, 5.0, and $7.5 \mathrm{wt} \% \mathrm{HGM}$, the reinforcement being incorporated at the $(\mathrm{Z1})$ feeding zone and at the extruder center (Z2), with statistical analysis.

variable for impact resistance reduction. Impact resistance was reduced for all the composites relative to values observed for $A B S / B$, since according to a study by Basurto et al. [20] with $A B S$ and glass fiber, impact resistance reduction and modulus of elasticity rise occur as a result of increased composite stiffness. A further factor for reducing impact resistance can be attributed to ABS shear during extrusion, promoting degradation of the elastomeric phase, butadiene, which is susceptible to thermomechanical degradation and also responsible for the ABS impact strength [15-17].

\section{Conclusions}

In this study, HGM-reinforced ABS polymer composites were prepared in a twin-screw extruder using two distinct feeding zones and different HGM loadings. The properties evaluated revealed that HGM plays an important role for composite reinforcement improving the stiffness and thermal stability of ABS. The results showed that HGM incorporation into ABS promotes density reduction, increased thermal stability and also increased stiffness as tested by results of storage modulus and tensile and flexural modulus of elasticity, increase in complex viscosity, and maintenance of tensile and flexural strength, with impact resistance diminished relative to ABS. The mechanical properties evaluated reached a maximum at $5 \mathrm{wt} \%$ of HGMs. Upon considering the most important properties for composites applications (impact strength, HDT, density, tensile, and flexural strength), it is observed that 
feeding zone Z2 showed the best results, probably because the integrity of the hollow glass microspheres was maintained, while $\mathrm{Z} 1$ zone showed better homogeneous reinforcement distribution as compared with Z2, but causing the break of HGM microspheres. This study shows that the properties of HGM-filled ABS matrix composites can be effectively controlled by adjusting the feeding zone and HGM content to develop light composites with higher mechanical performance that are potentially useful in the automotive industry.

\section{Competing Interests}

The authors declare that they have no competing interests.

\section{Acknowledgments}

The authors gratefully acknowledge financial support by the $3 \mathrm{M}$ Company as well as the University of Caxias do Sul.

\section{References}

[1] N. Gupta, R. Ye, and M. Porfiri, "Comparison of tensile and compressive characteristics of vinyl ester/glass microballoon syntactic foams," Composites Part B: Engineering, vol. 41, no. 3, pp. 236-245, 2010.

[2] A. S. Doumbia, A. Bourmaud, D. Jouannet et al., "Hollow microspheres-poly-(propylene) blends: relationship between microspheres degradation and composite properties," Polymer Degradation and Stability, vol. 114, pp. 146-153, 2015.

[3] P. A. Tres, "Hollow glass microspheres stronger spheres tackle injection molding," Plastics Technology, vol. 53, no. 5, pp. 82-87, 2007.

[4] J.-Z. Liang, "Tensile and flexural properties of hollow glass bead-filled ABS composites," Journal of Elastomers and Plastics, vol. 37, no. 4, pp. 361-370, 2005.

[5] B. Zhu, J. Ma, J. Wang, J. Wu, and D. Peng, "Thermal, dielectric and compressive properties of hollow glass microsphere filled epoxy-matrix composites," Journal of Reinforced Plastics \& Composites, vol. 31, no. 19, pp. 1311-1326, 2012.

[6] X. Lu, J. Qu, and J. Huang, "Mechanical, thermal and rheological properties of hollow glass microsphere filled thermoplastic polyurethane composites blended by normal vane extruder," Plastics, Rubber and Composites, vol. 44, no. 8, pp. 306-313, 2015.

[7] M. Y. Jo, Y. J. Ryu, J. H. Ko, and J.-S. Yoon, "Effects of compatibilizers on the mechanical properties of ABS/PLA composites," Journal of Applied Polymer Science, vol. 125, no. 2, pp. E231E238, 2012.

[8] R. M. Santos, G. Botelho, and A. V. Machado, "Avaliação da fotodegradação de ABS exposto a condições naturais," Ciência e Tecnologia dos Materiais, vol. 22, no. 1-2, pp. 87-90, 2010.

[9] B. Yalcin, S. E. Amos, A. S. D’Souza, T. K. Ista, C. M. Clemons, and I. S. Gunes, "Improvements in processing characteristics and engineering properties of wood flour-filled high density polyethylene composite sheeting in the presence of hollow glass microspheres," Journal of Plastic Film and Sheeting, vol. 28, no. 2, pp. 165-180, 2012.

[10] A. Boldizar and K. Möller, "Degradation of ABS during repeated processing and accelerated ageing," Polymer Degradation and Stability, vol. 81, no. 2, pp. 359-366, 2003.
[11] B. B. Difallah, M. Kharrat, M. Dammak, and G. Monteil, "Mechanical and tribological response of ABS polymer matrix filled with graphite powder," Materials and Design, vol. 34, pp. 782-787, 2012.

[12] J.-Z. Liang, C. B. Wu, and Z. C. Wei, "Correlation between impact strength and fracture surface fractal dimension of ABS filled with hollow glass beads," Polymers for Advanced Technologies, vol. 23, no. 1, pp. 108-113, 2012.

[13] H. Im, S. C. Roh, and C. K. Kim, "Fabrication of novel polyurethane elastomer composites containing hollow glass microspheres and their underwater applications," Industrial \& Engineering Chemistry Research, vol. 50, no. 12, pp. 7305-7312, 2011.

[14] H. Ma, L. Tong, Z. Xu, and Z. Fang, "Clay network in ABS-graftMAH nanocomposites: rheology and flammability," Polymer Degradation and Stability, vol. 92, no. 8, pp. 1439-1445, 2007.

[15] R. Scaffaro, L. Botta, and G. Di Benedetto, "Physical properties of virgin-recycled ABS blends: effect of post-consumer content and of reprocessing cycles," European Polymer Journal, vol. 48, no. 3, pp. 637-648, 2012.

[16] J. Li, X. Luo, and X. Lin, "Preparation and characterization of hollow glass microsphere reinforced poly(butylene succinate) composites," Materials \& Design, vol. 46, pp. 902-909, 2013.

[17] L. Jiang, Y. C. Lam, K. C. Tam, T. H. Chua, G. W. Sim, and L. S. Ang, "Strengthening acrylonitrile-butadiene-styrene (ABS) with nano-sized and micron-sized calcium carbonate," Polymer, vol. 46, no. 1, pp. 243-252, 2005.

[18] G. Tagliavia, M. Porfiri, and N. Gupta, "Analysis of flexural properties of hollow-particle filled composites," Composites Part B: Engineering, vol. 41, no. 1, pp. 86-93, 2010.

[19] J.-Z. Liang, "Mechanical properties of hollow glass bead-filled ABS composites," Journal of Thermoplastic Composite Materials, vol. 18, no. 5, pp. 407-416, 2005.

[20] F. C. Basurto, D. García-López, N. Villarreal-Bastardo, J. C. Merino, and J. M. Pastor, "Composites and nanocomposites of ABS: synergy between glass fiber and nano-sepiolite," Composites Part B: Engineering, vol. 47, pp. 42-47, 2013. 

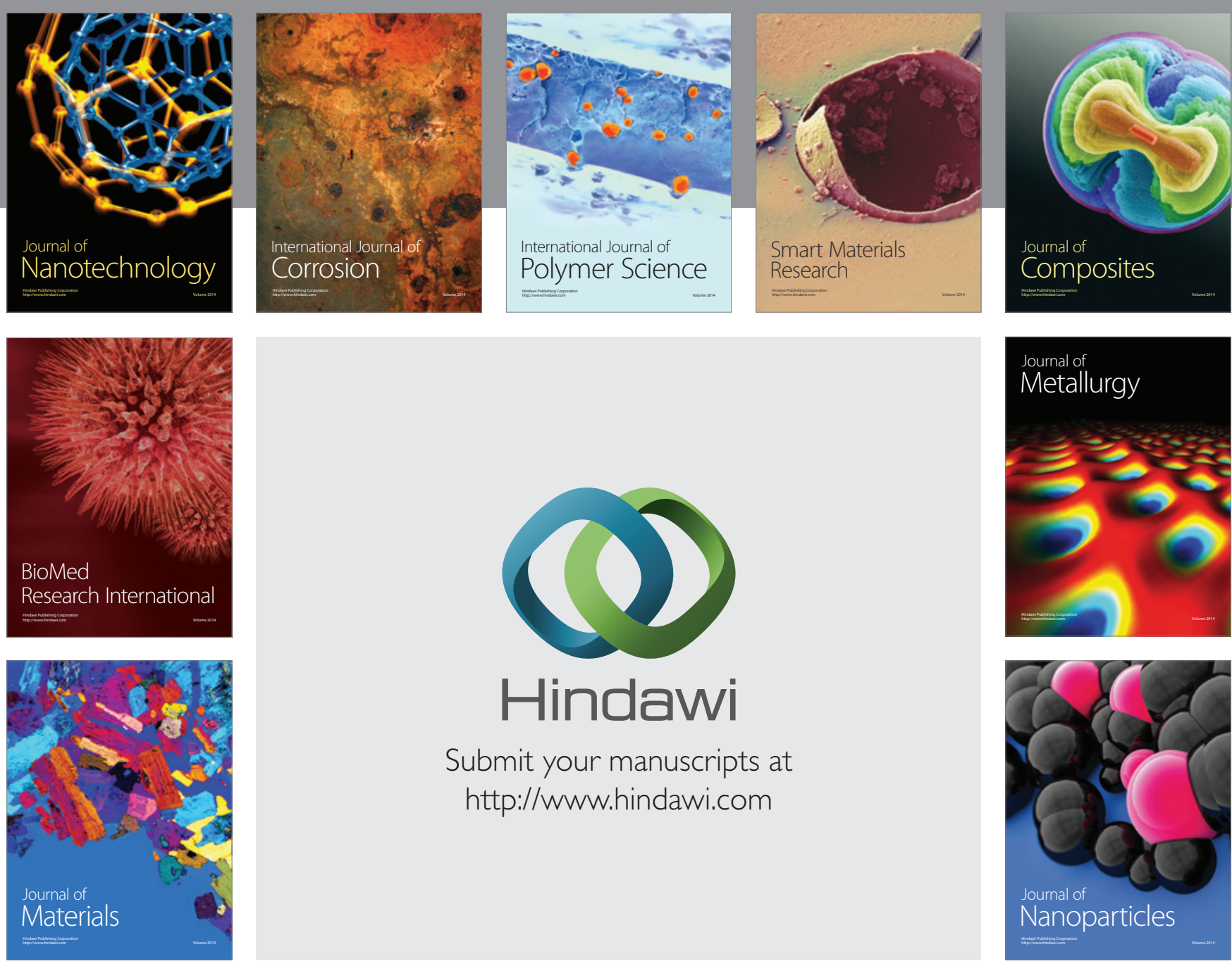

\section{Hindawi}

Submit your manuscripts at

http://www.hindawi.com

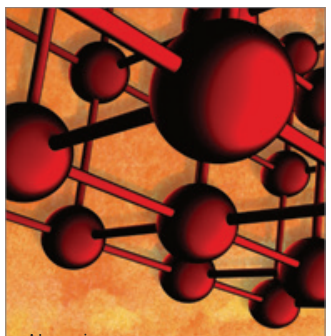

Materials Science and Engineering
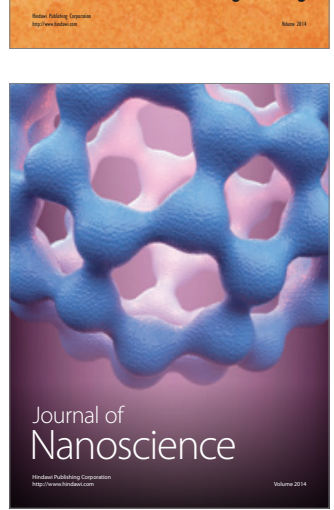
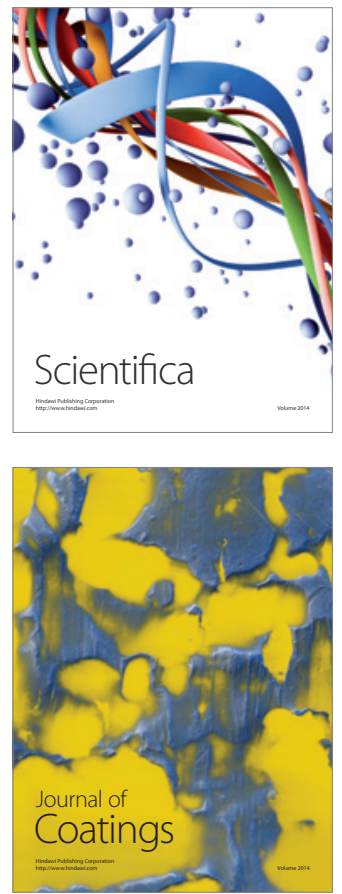
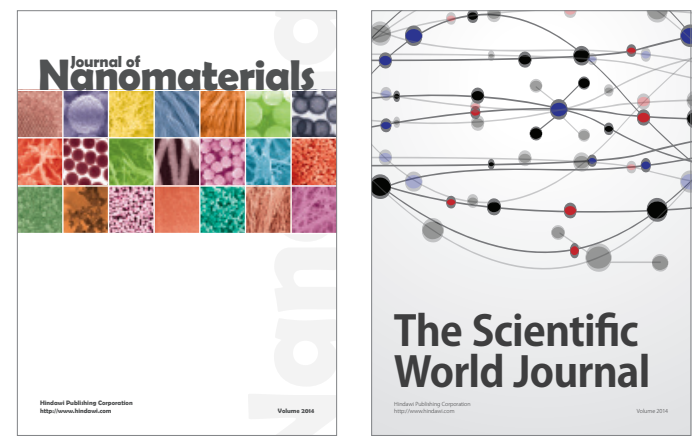

The Scientific World Journal
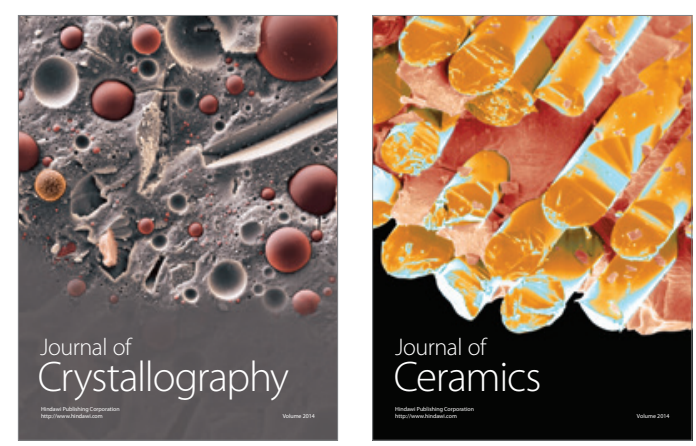
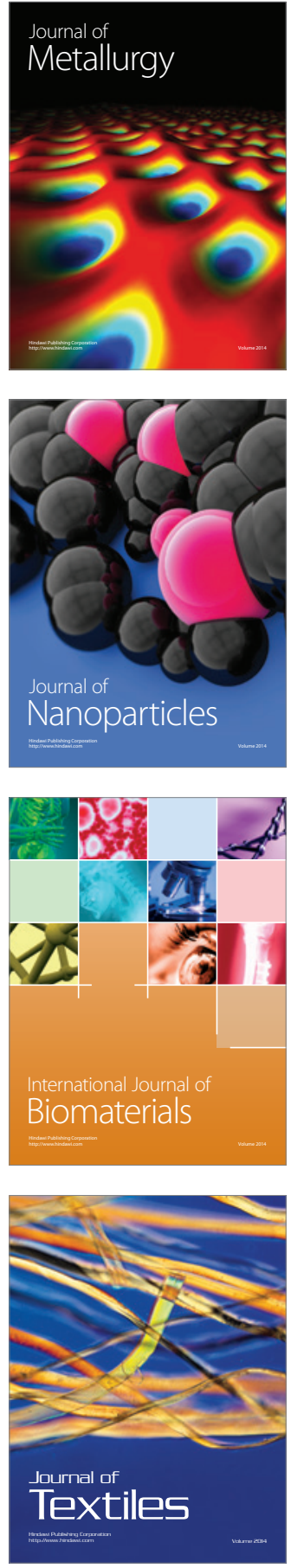